\title{
archOnline@JCU
}

This is the Accepted Version of a paper published in the Journal of Research in Science Teaching:

Tomas, Louisa, Rigano, Donna, and Ritchie, Stephen M. (2016) Students' regulation of their emotions in a science classroom. Journal of Research in

Science Teaching, 53 (2). pp. 234-260.

http://dx.doi.org/10.1002/tea.21304 


\title{
Research Article
}

\section{Students' Regulation of Their Emotions in a Science Classroom}

\author{
Louisa Tomas, ${ }^{1}$ Donna Rigano, ${ }^{1}$ and Stephen M. Ritchie ${ }^{2}$ \\ ${ }^{1}$ College of Arts, Society \& Education, James Cook University, 1 James Cook University Drive, \\ Townsville, QLD 4811, Australia \\ ${ }^{2}$ School of Education, Murdoch University, Murdoch, Western Australia, Australia
}

Received 30 June 2015; Accepted 24 November 2015

\begin{abstract}
Research aimed at understanding the role of the affective domain in student learning in classrooms has undergone a recent resurgence due to the need to understand students' affective response to science instruction. In a case study of a year 8 science class in North Queensland, students worked in small groups to write, film, edit, and produce short videos about the socio-scientific issue of coal seam gas mining as part of a unit on energy. Student emotions over the course of the unit of work were recorded using emotion diaries (a self-report measure), video recordings of lessons, and end-of-project interviews. We identify trends in student emotions and analyze their relation to classroom activities using two constructs for interpreting the affective dimension of student learning: emotional energy and emotion regulation. By analyzing a salient classroom event, we report students' regulation of negative emotions like frustration and anger as they worked together to complete the video project successfully. Furthermore, we propose that emotions, particularly positive emotions, elicited by the video task and not the socio-scientific issue dominated students' experiences and perceptions of the unit. This raises questions about how students' positive emotions might be regulated effectively so that they remain focused on the intended learning. (C) 2015 Wiley Periodicals, Inc. J Res Sci Teach 53: 234-260, 2016
\end{abstract}

Keywords: emotions; emotion regulation; emotional energy; socio-scientific issues; group work

When asked about past schooling experiences in science, students often recall particularly memorable events by describing the emotion they associate with these events; for example, "Making the wind turbines was fun" and "Dissecting the eye ball was disgusting." Alsop (2011) maintains that embodied displays of affect such as these shape all our practices. Osborne, Simon, and Collins (2003) note, "attitudes are enduring while knowledge often has an ephemeral quality" (p. 1074). This sentiment is particularly relevant to the students in our study - their recall of the content of their science lessons was far less impressive than their exuberant descriptions of activities that they perceived to be "fun" and "enjoyable."

Emotions are thought to affect students' learning and performance and are considered part of everyday school life (Goetz, Pekrun, Hall, \& Haag, 2006; Pekrun, 2000). In a classroom setting, students' emotions can influence the content of their cognitions, motivations, and actions, as well

Contract grant sponsor: Australian Research Council; Contract grant number: LP 110200368.

Correspondence to: L. Tomas; E-mail: louisa.tomas@jcu.edu.au

DOI 10.1002/tea.21304

Published online in Wiley Online Library (wileyonlinelibrary.com). 
as the way they process information (Boekaerts, 2007). Lewis (2008) asserts: "We need to give emotions the same status as cognitions. Just as cognitions can lead to emotions, emotions can lead to cognitions. The theory implies no status difference" (p. 745).

In spite of the "centrality of affect to teaching and learning," emotional perspectives remain under represented within science education research (Fortus, 2014, p. 821). At the same time, the complexity and dynamic nature of emotions in education makes this a difficult area of study (Linnenbrink-Garcia \& Pekrun, 2011). Some researchers have examined discrete emotions (Ainley, Corrigan, \& Richardson, 2005; King, Ritchie, Sandhu, \& Henderson, 2015), whereas others have focused on positive/negative affect (Boekaerts, 2007). Emotions may be transient, in-the-moment states or long-lasting traits (Hidi \& Renninger, 2006). While some studies have investigated the nature and emergence of emotions (Goetz, Frenzel, Pekrun, Hall, \& Ludtke, 2007), others have been concerned with the regulation of emotions (Nett, Goetz, \& Hall, 2011). Consequently, the methods used to explore emotions in education vary accordingly. The use of instruments to measure emotions is common (e.g., Chiang \& Liu, 2014; Heddy \& Sinatra, 2013; Pekrun, Goetz, Frenzel, Barchfeld, \& Perry, 2011), as is exploratory and qualitative methods employing interviews and self-reports (Orlander \& Wickman, 2011). Quantitative approaches have utilized modeling and statistical analyses (e.g., MacCann, Fogarty, Zeidner, \& Roberts, 2011). In-line with Pekrun and Linnenbrink-Garcia's (2014) assertion that the study of emotions calls for a "multimethod paradigm" (p. 664), Ritchie et al. (2016) have developed a suite of methods for identifying discrete emotions experienced by teachers and students, including qualitative video and audio analyses, that provide opportunities for detailed microanalyses of critical events in education settings (see also, Bellocchi \& Ritchie, 2015).

Curriculum content in science education often involves experiences or issues that evoke strong emotions. For example, dissecting animals may arouse disgust in some students, while high levels of curiosity may be elicited by a controversial topic such as stem cell research. How these emotions influence student learning and behavior in the classroom is now a significant research focus in science education. Emotions are considered a major influence on motivation for (Tuan, Chin, \& Shieh, 2005) engagement with (Tobin, 2005) attitudes toward (Broughton, Sinatra, \& Nussbaum, 2013) and interest in (Ainley \& Ainley, 2011) science.

Attending to the emotional responses of students and teachers doing science has the potential to open up ideas about relationships between pedagogies and learning. While sociocultural norms regulate emotions in certain settings, it has traditionally not been demonstrated in classrooms where the hegemony is a mind-body duality (Alsop, 2011). Orlander and Wickman (2011) assert that school science seems focused on removing the body from the science classroom. Discussing the implications of this duality, Milne and Rubin (2011) propose that "the need for teachers to listen to the emotional responses of students when they are engaged in actions and to use these responses as a resource for further interactions" (p. 632) is an idea that warrants further exploration by researchers.

In this study, we explored the emotions embodied by students as they engaged in a task that was designed to stimulate interest in a socio-scientific issue. This study builds on earlier research conducted by the first and third authors (Ritchie, Tomas, \& Tones, 2011; Tomas, Ritchie, \& Tones, 2011). Motivated by the need to promote the development of scientific literacy and to engage school students in the learning of science, this research investigated the effects of a writing-tolearn science project on participants' scientific literacy, science self-efficacy, interest, and perceived value of science. Significant improvements in these areas were reported for middleschool students. Tomas and Ritchie (2012) broadened the scope of their work by examining the role of year 12 students' emotions in learning science in this context. They reported that positive 
emotional responses such as pride, strength, determination, and alertness were elicited as students learnt and wrote about a socio-scientific issue.

Broughton et al. (2013) report an empirical link between emotions and learning about "hot" topics in science. For example, they found that students held negative emotions about the reclassification of Pluto as a dwarf planet. Targeted instruction assuaged these negative emotions and also facilitated both conceptual and attitudinal change toward the topic. While we posit that engaging with socio-scientific issues develops students' interest in science, through the arousal of valenced (i.e., positive and negative) emotions (Lundegard, 2007; Morris, 2014), it raises questions about students' regulation of their emotions in the science classroom.

The research presented in the current study is novel in that we monitor students' emotions in a context where they are given the opportunity to express science understanding of a socio-scientific issue using digital technologies. Our research is based on the assumption that it is possible to discern discrete emotions, such as enjoyment, pride, and frustration, in a classroom setting (Ainley, 2007; Ritchie et al., 2016). We also subscribe to the premise that the embodiment of strong emotions about a science topic can lead to increased interest and continued engagement in science (Collins, 2004). At the same time, student engagement is connected to the emotional energy residing in the interactions that occur in the classroom (Milne \& Otieno, 2007).

Specifically, this study investigates students' regulation of their emotions as they work to achieve planned outcomes in the science classroom. Drawing on sociological frameworks of emotion, two constructs for interpreting the affective dimension of student learning in science classrooms were consulted to interpret trends and themes in student emotions: emotional energy and emotion regulation.

In the sections that follow, we begin by describing the theoretical perspectives that inform our conceptions of emotions and learning, before defining our chosen constructs for interpreting the affective dimension of student learning in the current study.

\section{Theoretical Perspectives}

\section{Emotions}

The difficulty in defining exactly what emotions are lies with the reality that any definition will depend upon the researcher's perspective, whether it be biological, cognitive, cultural, structural, or behavioral. Turner's (2009) sociological theory of emotions maintains that emotions are one of the most critical micro-level social forces affecting not only "the dynamics of encounters where they are generated but also larger-scale social structures and their attendant cultures" (p. 208). Turner (2009) summarizes the research literature by identifying four primary emotions that all human beings experience: satisfaction-happiness, aversion-fear, assertionanger, and disappointment-sadness. Variants of the primary emotions occur when humans experience them at varying levels of intensity; for example, joy is high intensity happinesssadness, whereas dismay is moderate intensity disappointment-sadness (Turner, 2009). Combinations of these primary emotions produce more complex first-order emotions such as pride (anger plus joy). Second order elaborations are produced when all three negative emotions combine to produce shame, guilt, and alienation. Turner (2009) asserts that emotions are aroused by two basic conditions: "(1) meeting or failing to meet expectations and (2) receiving positive or negative sanctions from others" (p. 193).

Individuals will experience positive emotional arousal in an encounter if expectations for self, others, and the situation are met. When individuals perceive they have received positive sanctions from others, they will experience positive emotions and, therefore, be more likely to give positive sanctions themselves, creating a cycle that increases interaction rituals such as 
synchronization of talk and body language, sense of social solidarity, use of symbols to represent solidarity, and enactments toward these symbols (Turner, 2009). When expectations are not met and individuals receive negative sanctions, they will experience negative emotions, and unleash defensive strategies (in a bid to protect self) and mechanisms that decrease solidarity.

Turner (2007) identified five transactional needs that humans expect to be met in an encounter-verification of self, profitable exchange payoffs, group inclusion, trust, and a sense that participants are experiencing and sharing a common factual world (facticity). If these transactional needs are not met, individuals will perceive this failure as negative sanctions from others, leading to the arousal of negative emotions and activation of defense mechanisms such as repression, intensification, transmutation, projection, and attribution.

During emotional arousal, individuals will attribute outcomes of encounters to self, others, the structure of the encounter, or the cultural and societal structures in which the encounters are embedded. Lawler (2001) sees that arousal of positive emotions likely leads individuals to see self as responsible for rewarding outcomes and to, therefore, make self-attributions for these outcomes, while increasing solidarity with others and commitment to cultural and societal structures. Arousal of negative emotions, on the other hand, leads individuals to experience shame and guilt, and to make external attributions for outcomes, which decreases solidarity.

The current study asks students to diarize the emotions that they experience during interactions with other students, the teacher, and the curriculum content (see section Research Methods). We use these emotions as indicators of salient classroom encounters that activate students to meet their transactional needs by managing the course of interaction between individuals. The notions of emotional energy and emotion regulation fit appropriately with transactional needs and emotional arousal.

\section{Emotional Energy}

Insight into how interest and learning is cultivated through social interactions in science classrooms is offered by Collins' (2004) theory of social action that centers upon the idea that an interaction ritual (IR) arises when people physically gather together to focus attention on a common object or activity, constituting a group with clear boundaries. Emotional energy is a collective "long-term mood" (Collins, 2004, p. 107) that contributes to the emergence and reproduction of social solidarity. IRs can either motivate or demotivate group participants. Successful IRs generate and amplify motivating emotions and lead to high emotional energy through rhythmic entrainment where participants become attuned to the physical activity of others and share "a common mood or emotional experience" (p. 48). This builds solidarity and "collective effervescence." Humans are essentially motivated to attain more emotional energy and so seek further successful interactions in a series of self-reinforcing IR chains. Symbols of an interaction can also become charged with emotional energy and circulate in other rituals (or chains). These symbols act to reinforce the identities of participants, even when they are not gathered, thus serving to motivate them to act in accordance with the group's values. Failed IRs, on the other hand, drain emotional energy and demotivate. In this way, interest is shaped by the ritual situation and is socially formulated in words and symbols through successful IRs. Whether an individual shows interest for a specific knowledge, say science, depends on the ritual chains in which they participate and the way these rituals affect their emotional energy. Science classroom experiences that build emotional energy are likely to motivate students to pursue further experiences that generate emotional energy. Conversely, students will avoid pursuing experiences that drain emotional energy.

The link between emotional responses or states during classroom IRs and meaning making is illustrated in Orlander and Wickman's (2011) study of students' experiences during a sex 
education class. The content of the lesson was restricted to books due to the embarrassing subject matter. A companion meaning, besides the curriculum intent, was that the bodily reactions of embarrassment and shame had no place in the science classroom; yet, students longed for the opportunity to discuss the embarrassing nature of the topic because they considered the bodily reactions to be an important part of the learning. In another encounter, students experienced negative emotions during an eye dissection that interfered with learning. The teacher dismissed the revulsion felt by two students as "typical girls," yet was surprised when two boys expressed similar feelings. The teacher did not take the opportunity to acknowledge the potential for negative aesthetic experiences and provide strategies to mange the accompanying emotions. In this regard, the teacher behaved in a way that was historically consistent; where the accepted norm has been for teachers to embody the fact that science is context-independent and does not involve emotions. Yet, very few students can suppress their emotional responses by separating body and mind in classroom encounters.

\section{Emotion Regulation}

Emotion regulation refers to "the processes by which individuals influence which emotions they have, when they have them, and how they experience and express these emotions" (Gross, 1998, p. 275). It typically involves attempts to decrease one's negative emotions, while increasing their positive emotions (Pekrun, 2006). While Matthews, Zeidner, and Roberts (2002) suggest that emotion regulation requires recognizing and understanding one's emotions, managing them by employing particular regulation strategies, and using them to act or achieve a certain goal, emotion regulation can also occur unconsciously when triggered by environmental cues (Boekaerts, 2011).

An understanding of emotion regulation has the potential to enhance educational outcomes by informing the design of optimal learning environments and strategies to support student wellbeing over time (Jacobs \& Gross, 2014). Emotion regulation is also important to the ability to focus attention and apply the necessary mental processes for learning (Blair, 2002). Although there is evidence to suggest that the demands associated with regulating emotions may reduce the resources available to successfully complete learning tasks (Baumeister, Bratslavsky, Muraven, \& Tice, 1998), a more recent study found that emotion regulation was a unique predictor of children's early academic success and positively associated with classroom productivity and achievement (Graziano, Reavis, Keane, \& Calkins, 2007). Emotion regulation is necessary because students may abandon a learning activity when negative emotions, such as frustration, anger, boredom, and embarrassment, arise. To persist with a difficult learning task, students can seek IRs that build emotional energy, group membership, and solidarity.

Emotion regulation may be particularly relevant to group activities during science lessons. A study by Kershner, Warwick, Mercer, and Kleine Staarman (2012) found that primary students were able to manage themselves and others during science group work activities by regulating their own emotions in a way that was culturally acceptable within the classroom, leading to successful group learning. When technical issues arose, students found a way to handle uncomfortable experiences by invoking strategies such as "being patient." These strategies were the students' own constructions of the culturally accepted classroom principles established by the teacher for collaborative group work. Technical difficulties were identified as one of the reasons for students needing to invoke these strategies. Other reasons were for learning and achievement, and personal/social satisfaction.

In a study exploring the relationship between IRs and year 8 students' engagement with science, Olitsky (2007) found that sustained interest and a sense of group membership were instilled when the classroom environment provided a mutual focus for students to exchange ideas without risk, and with an appropriate level of challenge and time. Students became excited about 
balancing chemical equations, an abstract, and typically unpopular topic in chemistry, due to interactions where students invested emotional energy into the process of solving problems on the board, often resulting in applause for problems that were successfully solved. These feelings of solidarity with their fellow students promoted group membership and interest in the topic.

In the following sections, we define the research problem for our study and describe the methods we employed to track student emotions during science instruction on a topical socioscientific issue. We offer examples of students' regulation of negative emotions like frustration and anger as they completed a science assessment task. We analyze their emotional interactions in terms of their effectiveness in generating emotional energy that promoted group membership and mutual focus on science learning.

\section{Research Problem}

This study developed from a program of research that has seen students in years 6,9 , and 12 learn about the socio-scientific issue of biosecurity by writing a series of "hybridized" short stories that integrate scientific information (with consideration of relevant social and economic implications) within narrative storylines (see Ritchie \& Tomas, 2013). With a view to engage students positively in the learning of science, this research has found that writing short stories about a socio-scientific issue can stimulate students' interest and elicit positive emotional responses, while developing their conceptual understanding and more favorable attitudes toward science. While this research has convinced us of the cognitive and affective benefits of writing "differently" in science by employing the familiar genre of a narrative, we were interested to explore further how writing and telling stories about socio-scientific issues might implicate students' emotions.

In this study, year 8 students communicated stories about the socio-scientific issue of coal seam gas (CSG) mining through video. CSG mining is a complex and controversial socioscientific issue that involves multiple stakeholders, and requires consideration of scientific, social, economic, and environmental implications to develop an evidence-informed position on the issue. For this reason, we expected that this socio-scientific issue, as well as the complex process of collaboratively scripting and producing their videos, would arouse students' emotions. In the context of a potentially emotional topic and pedagogical approach, we were interested in investigating students' emotion regulation as they worked to achieve planned outcomes in the science classroom. In the following section, we detail our research design and procedures employed to investigate this research question, before presenting the outcomes of our study.

\section{Research Design and Procedures}

This case study (Stake, 1995) investigated the experiences of 28 students in a single year 8 science class (average age 13 years) and their teacher, Miss Murphy (pseudonym), at a coeducational urban school in North Queensland, Australia. The study was conducted in Semester 2, 2013, during a unit of work focused on Australia's energy future. As part of the unit, students explored Australia's current sources of energy and energy consumption, and the role that renewable energy sources might play in the future. The unit spanned a 9-week period, with three, 70-minute lessons per week (27 lessons in total).

Drawing on a multi-method approach, three complimentary sources of data were used to gain an insight into students' emotional arousal during the science lessons: an emotion diary, video recordings and observations of science lessons, and interviews with the students and their teacher at the end of the project. Quantitative analysis of students' emotion diaries was used to guide qualitative analysis of video recordings and observations of science lessons, by identifying salient classroom events that were signaled by the reporting of particular emotions at higher frequencies 
than others in given science lessons. End-of-project interviews probed participants' perceptions and experiences of the unit of work, and students' emotional arousal as they learned about the topic and worked collaboratively with others. Collectively, analyses of these data were used to identify trends in students' emotions and analyze their relation to classroom activities using two constructs for interpreting the affective dimension of student learning in classrooms, as outlined earlier in this paper: emotional energy and emotion regulation.

\section{Program Description}

Unlike the students in earlier studies, who wrote short stories about a socio-scientific issue (see Ritchie \& Tomas, 2013), the year 8 students, who participated in this research, told a story by producing short videos about CSG mining (3-5 minutes duration), at the school's request. Students were able to employ their imagination and creativity to communicate their understanding of the topic, so long as the videos educated viewers about CSG mining. At the time that this study was conducted, CSG mining was a topical socio-scientific issue that featured regularly in the media as it was actively explored as an alternative to generating electricity via coal-powered power stations in Australia. For this reason, it was selected by the head science teacher at the school as an appropriate topic for exploration in the context of the energy unit.

The video task required students to include the following information about CSG mining in their productions: the process of CSG mining and how it is undertaken; why CSG mining is being developed as an alternative to coal mining for coal-fired power stations, including the advantages of CSG mining over coal mining, the advantages of using CSG to generate electricity compared to coal, and the projected benefits of CSG mining, more broadly; and the impacts of CSG mining, including an explanation of the concerns that have been raised. To conclude their videos, students were prompted to evaluate evidence drawn from their research to adopt a position on CSG mining that considers the views of multiple stakeholders, including farmers, CSG companies, electricity consumers, and the environment (Figure 1).

The video task represented the culminating, summative assessment task for the energy unit. Students completed the task in small groups of four to six, of their choosing. In preparation for filming their videos, students worked collaboratively to write a script that contained a suitable storyline that embedded the required information about CSG mining, researched from the resources provided (i.e., websites about CSG mining from the Queensland Government Department of Natural Resources and Mines, conservation groups, and CSG exploration and mining companies; fact sheets about CSG; and online news articles and videos). Students could choose an appropriate plot for their script; however, they were encouraged to include characters that represented multiple CSG mining stakeholders. For example, a plot developed by some

What do you think?

a. Do you think that farmers should have a say as to whether or not coal reserves under their agricultural land are exploited to generate electricity? Consider the advantages and disadvantages of coal seam gas mining that you wrote about in Parts B and $\mathrm{C}$ to help justify your response.

b. Do you think that that coal seam gas mining should continue? Consider the advantages and disadvantages of coal seam gas mining that you wrote about in Parts B and C to help justify your response. You should also consider the viewpoints of farmers, coal seam gas companies, consumers of electricity (like yourself) and the sustainability of the environment.

Figure 1. An excerpt from the video task sheet that requires students to adopt an evidence-informed position on CSG mining. 
students in the class centered on a cattle farming family who were informed by a mining company that CSG exploration would commence on their property. Miss Murphy initiated the script-writing process by providing models of movie scripts and deconstructing the genre. She also helped students by providing formative feedback on their scripts prior to filming their videos.

As part of the unit, Miss Murphy engaged her class in a range of teaching and learning activities about renewable and non-renewable energy, including CSG mining, to help students learn about the topic and prepare for the video task. Activities included direct teaching of relevant key concepts; an exploration of renewable and non-renewable energy sources; building models of renewable energy sources and using them to conduct energy experiments; watching videos about sources of energy and answering questions; short research tasks; and worksheets.

\section{Data Sources and Analysis}

The emotion diary (a reliable self-reporting method for eliciting high school students' emotions, adapted from the work of Zembylas, 2007; see Ritchie et al., 2016) requires students to identify the most salient emotions they experience during class. Students are prompted by their teacher to complete a diary entry at the end of each lesson. The one-page template is composed of two parts. The first includes a table of nine emotion labels: excitement, happiness, enjoyment, pride, anxiety, frustration, disgust, annoyed, and disappointment. A 10th option is provided ("other") for students to indicate another emotion of their choice (e.g., enthusiasm, embarrassment, anger, fear, guilt, shame, etc.). Each label is accompanied by an "emoticon" to assist students to articulate the emotions they may have felt. Students are required to circle the emotion/s they most strongly experienced during the lesson, and, beside each one, provide a brief explanation of what they were doing or what happened when they experienced the emotion, and at what or whom the emotion was directed. The second part of the diary is composed of a 10-point scale for students to indicate their level of interest during the lesson, such that a score of 1 corresponds to "ver bored," and 10 corresponds to "very interested." A neutral mid-point is provided. As some researchers have disputed the classification of interest and boredom as emotions (Do \& Schallert, 2004; Wosnitza \& Volet, 2005), the interest scale is simply used heuristically to identify salient classroom events.

Given that the emotion diary is a self-report measure that requires students' cooperation to complete, Tomas (the first listed author) spent approximately 40 minutes during the first science lesson at the start of the unit to introduce and explain the significance of the research and the emotion diary. The diary includes a short description on the first page that helps to explain how students might recognize an emotion, such as experiencing a particular feeling, or sensing a physiological (bodily) change (e.g., their heart rate or breathing changes). This was discussed first, and students were offered the chance to share how they recognize when they are feeling particular emotions (e.g., "I know when I'm angry, because I can feel my face getting hot" - a physiological response). Following on from this, the nine emotion labels were reviewed, one by one, to develop a shared understanding of each. Their meaning was discussed as a class, and students were invited to share examples of circumstances that they had experienced in science class to elicit different emotions (e.g., "I felt proud when I got a good score on my last science test"). The students then practiced completing a test entry in the emotion diary to ensure that they were comfortable providing the information, and to answer any questions they may have had. The interest scale was also discussed so that students understood how to use it.

Although the emotion diaries do not provide data regarding "in-the-moment" emotional experiences (Wosnitza \& Volet, 2005), they are useful for identifying general patterns, consistent with interpretive research (Erickson, 1986), and to identify salient classroom events-events that led students to self-report particular emotions at a higher frequency than others-worthy of closer 
investigation. Data from the first section of the emotion diaries were analyzed quantitatively by counting the frequency that each emotion was reported each lesson. For interest, a mean score on a scale of 1-10 was calculated by averaging students' responses to the interest scale. Both the emotions and interest data are presented graphically and used heuristically to identify salient classroom events that elicited high counts of particular emotions, or high or low levels of interest. Any qualitative data provided in the first section of the diary (i.e., explanations of why particular emotions were elicited) were coded manually and analyzed inductively to identify prominent themes. These data were used to triangulate classroom observations and video recordings, and to develop questions for the end-of-project interviews.

Video recordings of each science lesson complemented data drawn from the emotion diaries. A video camera was set up in the classroom to capture student-student and teacher-student interactions. For part of the project, students worked in small groups outside the classroom. In these instances, a single group was followed. Groups were identified based on the researchers' observations of students who outwardly expressed their emotions (e.g., through vocalizations, facial expressions and gestures) and by reviewing students' emotion diaries (i.e., through diary entries that indicated strong feelings about their experiences in the classroom).

Qualitative analysis of the video recordings was guided by analysis of the emotion diaries, such that sections of video that corresponded to salient events identified from the emotion diary data were reviewed. The videos were analyzed for outward expressions of students' emotions and other significant interactions, such as facial expressions (e.g., a puzzled look), emotional vocalizations (e.g., a shrill tone of voice or laughter), gestures (e.g., placing one's head in their hands), or actions (e.g., withdrawing from a group).

Given that spontaneous facial expressions can be accurate indicators of emotions, they can be analyzed qualitatively to provide evidence of in-the-moment emotional arousal (Keltner \& Ekman, 2000). The Facial Action Coding System (FACS) developed by Ekman and Friesen (1978) is an anatomically based system that measures visible facial behaviors. The FACS has been used extensively in empirical studies of facial measurement (Rosenberg, 2005), including earlier studies by the first and third authors (e.g., Tomas \& Ritchie, 2012; Ritchie et al., 2016). In this study, in the absence of full-frontal images of subject's faces that would permit the application of facial recognition software, manual procedures for interpreting students' facial expressions were applied, according to Ekman and Friesen (1975). This analysis of students' spontaneous emotional expressions captured on video complemented the self-reported data recorded in their emotion diaries.

Rigano (the second listed author) conducted end-of-project, semi-structured interviews with six students. These students were identified through the researchers' own observations of students who appeared comfortable articulating their emotions during the project through their diaries. Classroom observations and a review of students' emotion diaries were used to develop questions and issues for exploration in the interviews, including general questions about their experiences and perceptions of the unit of work and the topic (e.g., Tell me what you learned about CSG this term? How did you feel when you learned about some of the impacts of CSG on people or the environment?); questions about working collaboratively with others (e.g., How did you work with the members in your group to complete the video task?); and questions related to their emotions and emotion diary entries (e.g., What was the strongest emotion you felt this term in science? Tell me more about you wrote here in your emotion diary. . .). Miss Murphy also participated in a semistructured interview at the end of the project, and was asked about her perceptions of her students' learning and engagement during the term; her experience of teaching the unit and of using the emotion diaries; and whether being cognizant of students' emotions impacted on her teaching of the unit. 


\section{Student Regulation of Emotions}

In this section, we present a case as evidence that students regulated their negative emotions during ongoing group work to complete the video task successfully. This finding arose from the analysis of a salient classroom event that investigates the emotion regulation of a group of students as they worked together over a series of lessons during the production of their video. In this case, students were motivated to regulate their emotions by the desire to finish the task, to achieve good grades and to preserve friendships. We also provide evidence to support the finding that emotions associated with producing students' videos, particularly positive emotions, dominated their experiences and perceptions of the unit. Students reported very few emotions as being aroused by the socio-scientific issue itself.

The case presented herein was identified by examining trends in emotion diary data. Figure 2 presents a summary of students' mean interest levels across the course of the energy unit. Overall, students' mean interest scores varied between 5.7 (lesson 4.1) and 9.1 (lesson 8.1), noting that scores higher than 5 represented "interested," while those less than 5 represented "bored." The mean interest score for the entire unit was 7.7, which suggests that this group of students was generally interested during the science lessons. On average, $11 \%$ of students $(N=3)$ chose not to respond to the interest scale. A visual analysis of the graph in Figure 2 reveals a number of peaks and troughs in students' interest across the course of the unit. While students' interest levels dropped in particular lessons (e.g., lessons 2.1, 3.1, and 4.1), it generally improved in the next lesson or two. Notwithstanding these fluctuations, there is a steady decline in interest following a peak in lesson 8.1 ( $M=9.1$ ), to the end of the unit (lesson 10.1, $M=6.48$; Figure 2, point a), which appears atypical. While the range in students' interest scores was relatively low $(R=3.4)$, these fluctuations in interest levels are nonetheless significant in the context of these students' perceptions, and led us to examine more closely the corresponding emotions data drawn from these lessons.

Figure 3 presents an overall count of each of the emotions reported in students' emotion diaries, while Figure 4 presents a detailed summary of the emotions reported in each lesson. Given that students generally expressed quite high levels of interest throughout the unit of work, it is not surprising that positive emotions were reported most frequently; namely, excitement, happiness,

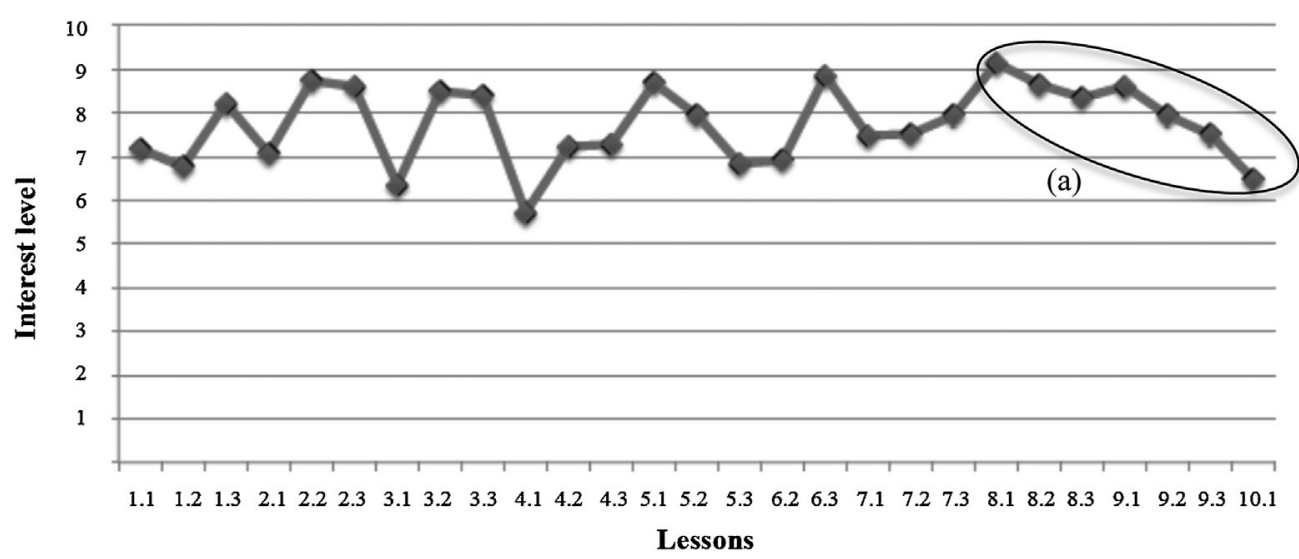

Figure 2. Students' mean interest levels across the course of the energy unit. Note that the lessons are numbered such that the first digit represents the week (weeks 1-10), while the second digit corresponds to the lesson number in a given week (lessons 1-3). [Color figure can be viewed in the online issue, which is available at wileyonlinelibrary.com]. 


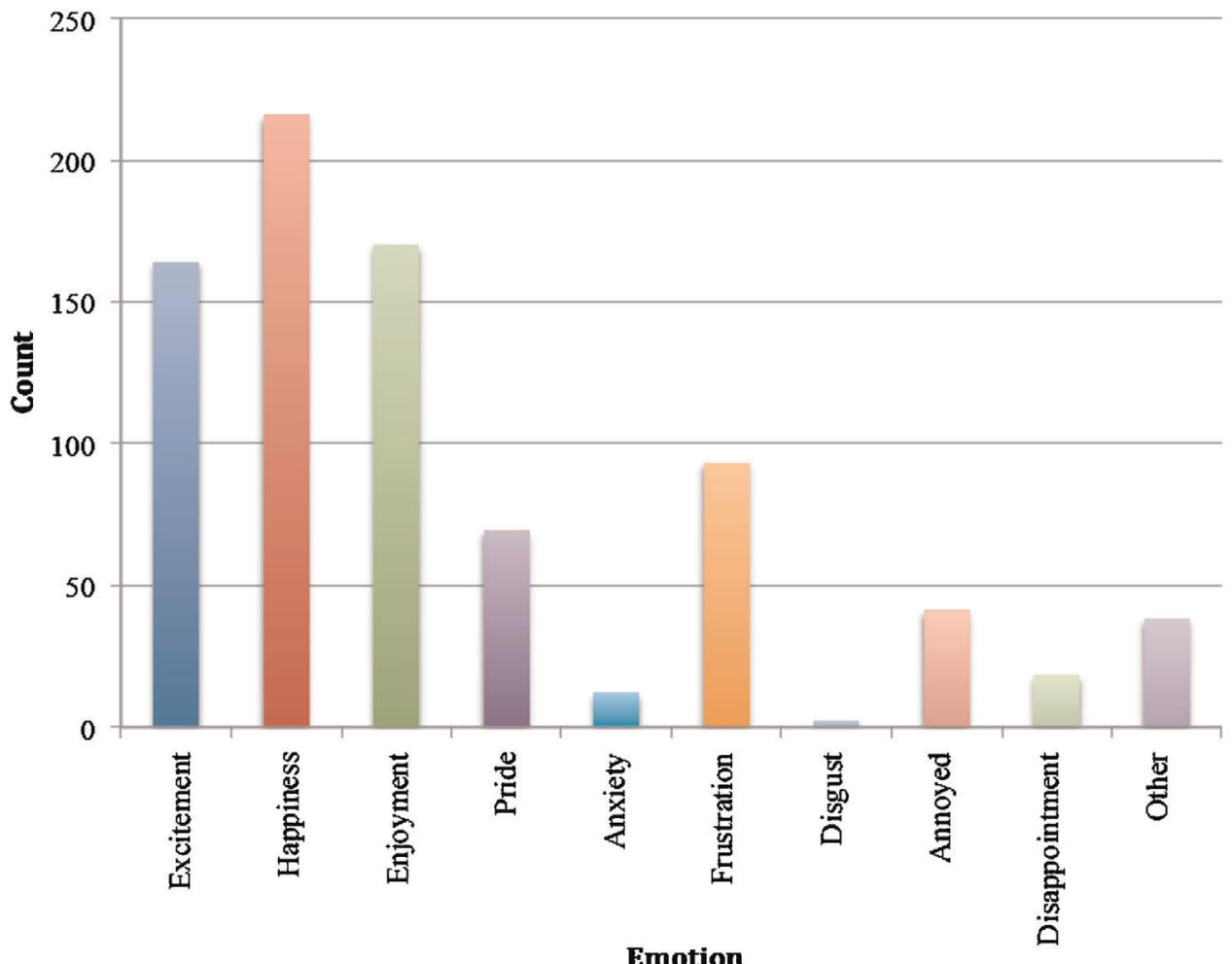

Figure 3. An overall count of each of the emotions reported by students in their emotion diaries.

and enjoyment. Low counts of negative emotions and other emotions/feelings were reported (i.e., enthusiasm, low confidence, argumentative, tired, unsure, bored, confused, irritated, and weird), with the exception of frustration, which stands out as being reported more frequently than the other negative emotions.

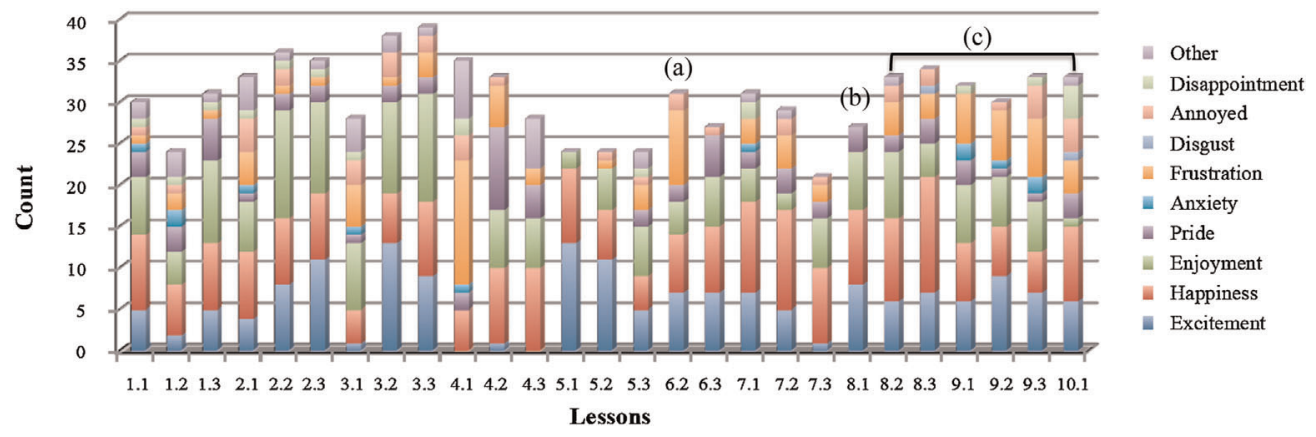

Figure 4. A detailed count of each of the emotions reported by students in the emotion diaries, lesson by lesson. Note that the lessons are numbered such that the first digit represents the week (weeks 1-10), while the second digit corresponds to the lesson number in a given week (lessons 1-3). 
In coming to understand what transpired in lesson 8.1 and the lessons that followed, we learned that students commenced filming their videos in lesson 8.1, which coincided with high counts of positive emotions and no reports of frustration (Figure 4, point b). In lessons 8.2-10.1, a steady decline in interest corresponds to students' continued filming and editing of their videos (Figure 4, point c). This series of lessons also yielded consistently higher counts of frustration than previous lessons. As we looked back through the data, we found that students began planning and scripting their videos in small groups in lesson 6.2 (Figure 4, point a). This lesson is also marked by higher counts of frustration than preceding lessons. Lesson 6.2, therefore, represents the first lesson that the students' began working collaboratively on the video task by scripting their videos, while lesson 8.1 signaled the start of filming.

Collectively, these trends in students' self-reported emotions and interest levels highlighted a number of lessons worthy of closer examination by way of the video recordings, which revealed the case reported in this paper. In the section that follows, we begin by reviewing the case to reveal how a group of students came to regulate their negative emotions during the completion of the video task.

\section{Student Regulation of Negative Emotions During Group Work}

In this case, we focus on a small group of students, and, in particular, two members of the group-Tim and Josh—who regulated their negative emotions while collaboratively filming their video. While this was a high-achieving group of students, they nonetheless experienced difficulty in their group interactions as they worked together on the task. As such, these students are representative of other groups in the class who experienced similar difficulties in working together. Tim and Josh were among five students who collaborated to complete the CSG mining video task. While both students were confident and actively participated in the group, Tim demonstrated a tendency to lead the group, and although a group leader was not officially appointed by the students, Tim naturally assumed this role and directed the way in which filming the scenes for their video progressed.

In lesson 8.1, students commenced filming their videos. Enjoyment, happiness, and excitement (Figure 4, point b), and a high level of interest ( $M=9.1$, Figure 2) characterized this lesson. Tim and Josh's group began scouting the school grounds for suitable locations to film the scenes for their video. The enjoyment indicated in both students' emotion diary entries for this lesson is indicative of the emotions elicited by the class (Tables 1 and 2).

In lesson 8.2, the group began filming. Tensions began to arise, however, when the boys disagreed about how particular scenes should be filmed, and fought to have their own ideas heard. These tensions were reflected in Josh's emotion diary entry: "Frustrated: Everyone was taking over the assessment" (Table 1). Tim's diary entry mentions an argument during recording, although his entry is incomplete (Table 2). At interview, Tim explained how his frustration arose when the group members stridently disagreed on how filming should proceed, and how individuals tried to "take over," as recorded in Josh's diary:

It was part of the filming that people started to take over. Like, we'd be doing a bit and all decide just one thing and one person in the group would say, "No I'll do that." Everyone would just have to listen to them and start fighting over it. We just couldn't make decisions in the classroom about how we would film the next bit. It got really frustrating. (Tim, Excerpt 1)

As the week progressed, it became evident that some students' voices were being heard over others. In particular, Tim began to dominate the group's decision-making, while 
Table 1

Josh's emotion diary entries for lessons 8.1-10.1

\begin{tabular}{lllc}
\hline Lesson & Emotion(s) & \multicolumn{1}{c}{ Explanation } & Interest Rating \\
\hline 8.1 & Enjoyment & Finding places to film in the school. & No rating \\
8.2 & Frustration & Everyone was taking over the assessment. & No rating \\
8.3 & Frustration & Because no one listens to me. & 1 \\
9.1 & No diary entry—absent from class. & \\
9.2 & No diary entry—absent from class. & People are fighting with each other about the assessment. & No rating \\
9.3 & Frustration & Peo are done [sic] our assessment. & We \\
10.1 & Happiness & We
\end{tabular}

Note: Josh did not rate his level of interest for a total of four lessons during the school term.

Josh became increasingly angry and frustrated at not being listened to. This tension came to a head in lesson 8.3. Figure 5 depicts a series of images drawn from a video recording of the group as they worked to film a scene. Approximately 5 minutes after filming commenced, the boys attempt to shoot a scene but are unhappy about how it plays out. Two boys are filming, while Tim and another student, Matthew, feature in the scene. Josh watches on. When they are finished, the four boys stand back and discuss how they might shoot it again, agreeing to resume mid-way through the scene. Josh interjects: "We should actually film from the start," but his suggestion is ignored. At that point, Josh retreats from the group and slumps down, sitting against a brick wall. A few seconds later, he puts his head down against his arms, before lifting his head. His facial expression reveals that he is angry, as signaled by changes in his eyebrow, eyelids and lips (05:40). The inner corners of Josh's eyebrows are drawn together and lowered, and his eyes are tense. His chin is wrinkled, and he is expressing a "lip-pressed-against-lip pout" (Ekman \& Friesen, 1978). Josh remains seated for the next few minutes while the group continues to discuss ideas without him. Josh's gestures alternate between putting his head down against his arms, throwing pebbles and cursing - actions that are consistent with his expression of anger.

At 06:39, the group cannot agree on whether to position the camera behind or in front of a tree for a scene. Josh offers another suggestion: "Do it from behind. The one from behind looks better." Again, the other group members do not acknowledge his suggestion and continue their

Table 2

Tim's emotion diary entries for lessons 8.1-10.1

\begin{tabular}{|c|c|c|c|}
\hline Lesson & Emotion(s) & Explanation & $\begin{array}{l}\text { Interest } \\
\text { Rating }\end{array}$ \\
\hline 8.1 & Enjoyment & As recording is getting closer and I am excited. & 10 \\
\hline 8.2 & $\begin{array}{l}\text { Other [not } \\
\text { indicated] }\end{array}$ & Recording was just an argument about how we didn't $[s i c]$. & 3 \\
\hline 8.3 & Annoyed & $\begin{array}{l}\text { Because I had to do my whole speech again because [group } \\
\text { member] deleted it. }\end{array}$ & 6 \\
\hline 9.1 & No diary entry & absent from class. & \\
\hline 9.2 & Annoyed & Because people keep interrupting me in the video making. & 6 \\
\hline 9.3 & Enjoyment & Because we are editing. We are back on track. & 10 \\
\hline 10.1 & Happiness & We ARE DONE!!! & 10 \\
\hline
\end{tabular}



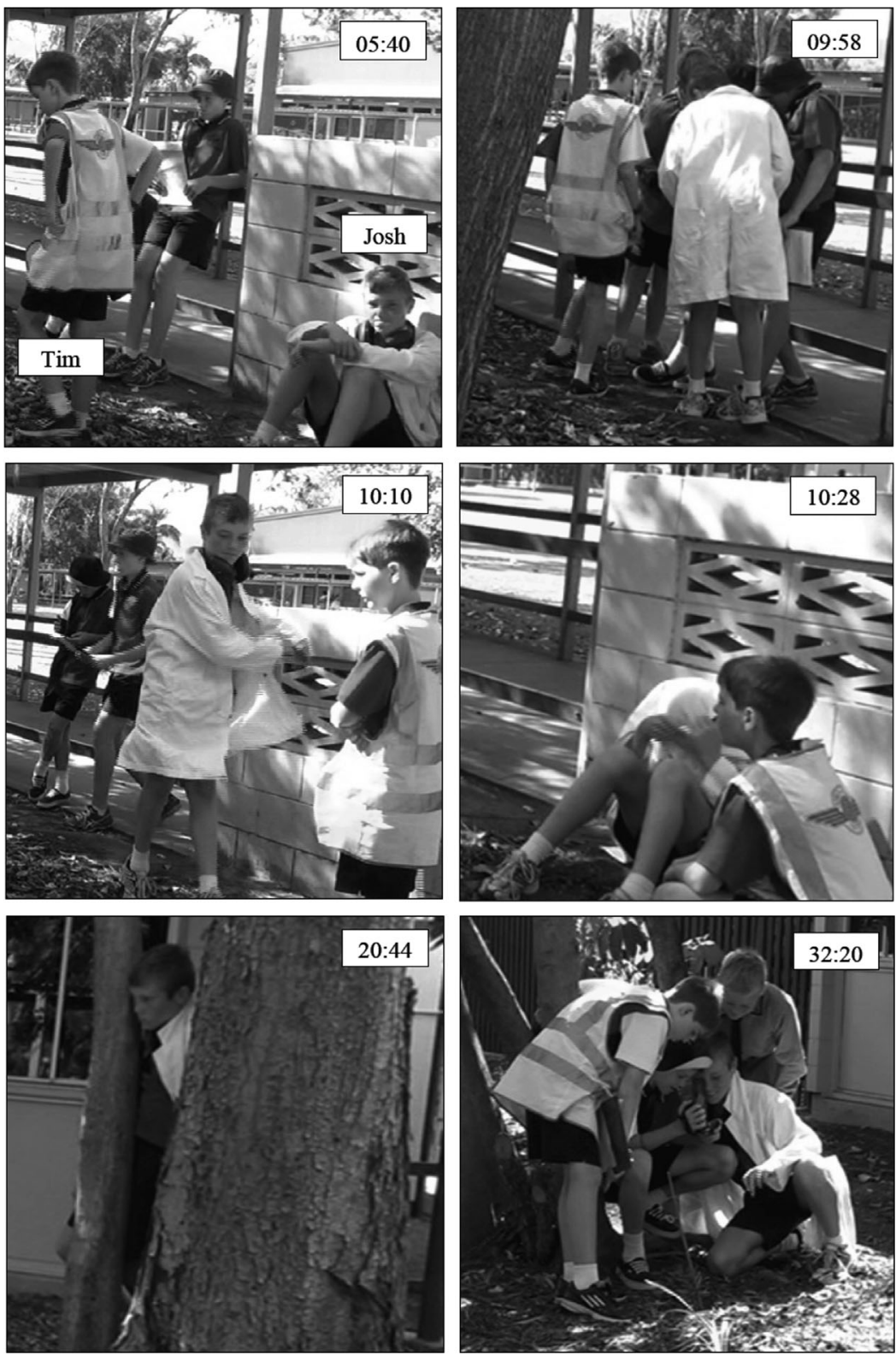

Figure 5. A series of images drawn from a video recording of lesson 8.3, as Tim and Josh's group film a scene for their CSG mining video. The number accompanying each image represents the time in the video sequence (minutes:sececonds).

deliberations, led by Tim. Josh throws a stick in Tim's direction that lands at his feet, seemingly in a bid to gain his attention.

At 07:29, Tim is leading a conversation with Matthew about how his character will enter the scene. Again, Josh offers a suggestion; but this time, Tim openly dismisses his idea: 


\title{
Excerpt 2
}

\begin{abstract}
Matthew: As I'm saying, ah, "You need to give us the government's recommendations," you can walk in.
\end{abstract}

Josh: And then yous [sic] turn around and start talking.

Tim: And then, and then [voice raised] I start talking and we start walking backwards.

Josh: Yeah, no, but turning around.

Tim: Turning around would just look weird.

Over the next few minutes, the group films part of the scene again, while Josh remains seated against the wall. At 09:58, Josh joins the group to review the footage on the camera. After following Tim's advice as to how the scene should be filmed, they are still unhappy about how it looks. Josh is visibly upset that the footage is no good, particularly after his suggestions were ignored. While the group decides to shoot the scene again, Josh walks away, throwing a pebble hard at the ground (10:10). This expression of physical aggression and his tightly pressed lips signal anger (Ekman \& Friesen, 1975). He slides down and sits against the wall again, with his head in his hands, and curses under his breath. Tim walks over and crouches down beside him, as Josh pulls his costume over his head and hides his face (10:28). Tim remains close to Josh but does not speak while the other members of the group discuss the scene again.

The group continues to discuss their filming decisions and shoot small sections of footage, without active input from Josh. Instead, he wanders to and from the group, listening and observing; however, he is still visibly frustrated, resting his forehead on his outstretched arm as he leans on a railing. At times, Josh distances physically himself from the others.

Toward the end of the lesson, there is a change in the group dynamic. As the students finish filming the scene, they huddle together to play it back on the video camera. Josh joins in, and all of the boys laugh and joke as they watch the footage (32:20). Upon returning to the classroom, all of the group members stand around Miss Murphy to show her the scene on the camera (Figure 6). As Miss Murphy praises the group for the work that they have done, Josh's facial expression is that of a "felt smile" (the corners of the lips are pulled up towards the cheek bones, and naso-labial folds extend out from the nose and down the area beyond the corners of the mouth), which is indicative of happiness (Ekman \& Friesen, 1978).

While the lesson appears to end positively for Josh, Tim and their fellow group members, Josh's emotion diary entry (lesson 8.3, Table 1) records frustration (moderate intensity angeraversion; Turner, 2007): "Because no one listens to me." His interest rating for this lesson is also very low (1). It is clear, based on Josh's outward expression of negative emotion during filming and in his emotion diary entry, that the group dynamics had bothered him. In particular, he appeared unhappy that the group did not take up his ideas, and so, he was not an active participant in the process.

Tim also recorded a negative emotion in his emotion diary entry for this lesson. He was annoyed because his scene had to be filmed again after the student using the camera accidentally deleted it. In spite of the fact that he was clearly aware of Josh's frustration during the lesson (e.g., Figure 5, 10:28), he made no mention of the group dynamics in his diary entry. In Tim's diary entry for the next lesson (9.2), he is also annoyed "Because people keep interrupting me in the video making," presumably as he struggles to maintain some leadership of the filming process. In spite 


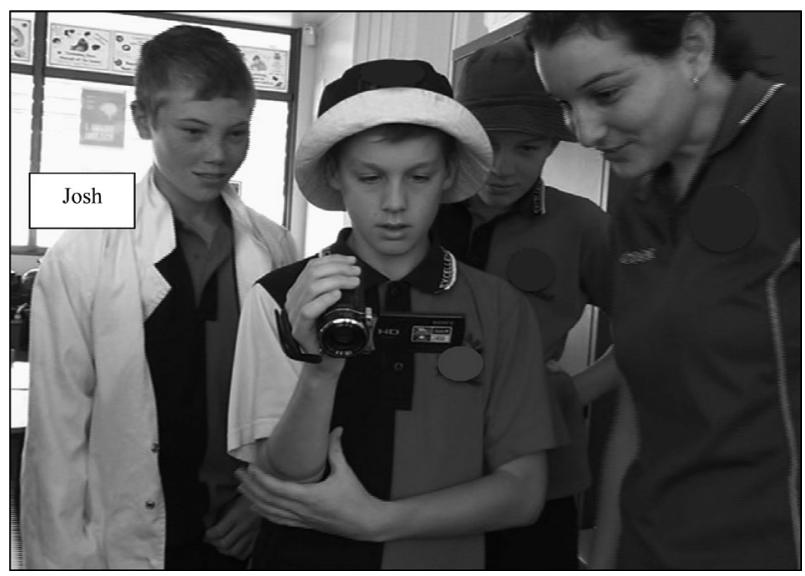

Figure 6. An image taken at the end of lesson 8.3, after the group has returned to class. They are showing Miss Murphy (far right) the scene that they had just finished filming during the lesson.

of this, Tim records a moderate level of interest in the lesson (6). This is the last lesson that the group films before editing their video in the classroom (lesson 9.3). Josh was absent from lessons 9.1 and 9.2.

Josh and Tim's experience of the editing lesson (lesson 9.3) appears vastly different, based on their emotion diary entries. Josh is still frustrated, as members of his group cannot agree on editing decisions ("People are fighting with each other about the assessment;" Table 1). Again, this lesson elicits a low level of interest for Josh (3). Tim, however, enjoyed the lesson, and does not acknowledge any tension in the group: "Because we are editing. We are back on track" (Table 2). In contrast to Josh, his interest level spikes (10).

Notwithstanding the challenges of working collaboratively on the task, the group managed to successfully produce a video to submit for assessment. Both Josh and Tim expressed happiness in the emotion diaries at having completed the task (e.g., Tim: "We ARE DONE!!!," Table 2).

At interview, both students recalled the difficulty that they experienced working together. For Tim, negative emotions arose when the other members of the group did not share the same work ethic as him. He recalled his annoyance (i.e., low intensity assertion-anger; Turner, 2009) at his peers laughing and "being silly" when they should have been focused on the task at hand:

Sometimes when we were recording we were going to do bloopers but sometimes people made too many mistakes and were just being silly about it. When I was doing my bit, lots of people were walking by and people were throwing sticks across our camera and that, so I was getting a bit annoyed where everyone else, they were having a laugh. (Tim, Excerpt 3 )

Tim went on to explain that while he enjoyed science, working with his group proved to be a significant challenge, which he reflected on at home:

I said to my Mum that science was my favorite subject and I was starting to get annoyed with my group members ... It's [i.e., working in a group] more difficult than I thought it would be. Especially with everyone else's opinion. Like, I know that I was a bit hard on everyone when I was recording Josh's bit because I would think one bit and then another person would think that bit I would just want whatever's best but I thought mine was always best, but I knew that other people had opinions too. (Tim, Excerpt 4) 
In this excerpt, Tim acknowledges that he was "a bit hard on everyone" when Josh's scene in the video was being filmed, and the difficulty that he experienced in acknowledging the opinions of others, particularly as he thought that his ideas were "always best." This is likely to have contributed to Josh's frustration at not being listened to, as recorded in his emotion dairy (lesson 8.3, Table 1).

While Josh's negative emotions appeared to get the better of him during lesson 8.3, an analysis of the group's interactions did not reveal what led him to regulate these emotions and rejoin the group. At interview, however, Josh provided some insights into what transpired. For him, the motivation to regulate his frustration arose, in part, from the desire to maintain friendships. While his negative emotions were linked to arguments occurring within the group, and his experience of not being listened to, he explains in the following excerpt that the group task was "just an assignment" that was not worth losing friendships over. Josh also explains the group's strategy for progressing the filming process (i.e., granting autonomy to individuals who feature in a scene):

In the end, we just decided to not fight, like stay friends because it's just an assignment. So we just ended up working it out and we can't change it. So it's whoever's bit it is, that person decides what they're going to do. If it's not good at all though they can change it. But if it was good enough that's what we were going to do. Everyone else will just have to deal with it. (Josh, Excerpt 5)

It's interesting to note Josh's comment that, during filming, "whoever's bit it is, that person decides what they're going to do ... everyone else will just have to deal with it," in light of his apparent frustration and difficulty in "dealing with" Tim and Matthews' creative decisions when filming their own scene (Figure 5). Perhaps this was a realization that Josh came to upon reflection, once the video was completed.

In addition to maintaining friendships, the motivation to regulate negative emotions appeared to also arise from the desire to achieve a common goal-to finish the CSG mining task successfully-and to do well. Josh explained at interview that the students in his group were high achievers who wanted to get "good marks." This motivated them to do a good job, in spite of the challenges in working together: "Because we all wanted to get good marks, pretty much everyone in the group are B or A [grade] students. So they all wanted to keep their marks up ..." (Josh). Indeed, this group of students did achieve a good grade for the task, an A-. The group's motivation to do well was also highlighted when Josh explained that there were some difficulties with one particular scene in the video that required re-shooting. They did not have all of the necessary props and costumes, so filming the scene again would mean that it would not look quite right. The members of the group weighed up some slight imperfections against leaving out an important section of the film:

Miss [Murphy] was saying that we could just leave it out, everyone was like thinking about that. But a couple of us, no we didn't want to lose marks, because it would mark us down Miss said ... So we went back and did it again. (Josh, Excerpt 6)

Miss Murphy also recognized her students' self-regulation and persistence in working together, and dealing with the technical issues associated with filming and editing their videos. She commented at interview:

They [the students] were saying yesterday that it really tested their patience with the editing, and I can understand that because it's not an easy task, but they handled it really well. Like, 
all your frustrations as a group, and losing files, and re-shooting files and all of that, through all of that, they haven't got cranky, they didn't give up. They just kept going. (Miss Murphy, Excerpt 7)

Although Josh and Tim's group successfully scripted, filmed and produced a short video on CSG mining for their assessment, Tim explained at interview that he did not enjoy this science unit because there were too many arguments within his group, which led him to experience emotions such as frustration, anger and annoyance. He commented that, rather than produce a video, he would have preferred to develop a PowerPoint ${ }^{\mathrm{TM}}$ presentation or a chart about CSG mining, and either work on his own or in a pair: ". . maybe $[a]$ one or two person thing" (Tim).

\section{Student Regulation of Positive Emotions}

The case reported above illuminates the negative emotions elicited by the CSG mining task for Tim and Josh, and their regulation of these emotions. An examination of what aspects of the energy unit elicited particular emotions across the class reveals, perhaps not surprisingly, it was the nature of the CSG mining task (i.e., scripting and producing a short video in groups), and not the socio-scientific issue of CSG mining itself, that elicited the most emotions, as reported in students' emotion diaries (Table 3). Activities earlier in the unit, such as energy experiments (lessons 3.2 and 3.3) and watching a video about energy (lesson 2.1) elicited a high number of positive emotions $(N=118)$, and very few negative ones $(N=5)$. While filmmaking elicited a similar count of positive emotions $(N=119)$, such as excitement, happiness and enjoyment, it also drew the highest count of negative emotions $(N=26)$, like frustration and annoyance. The process of researching and writing scripts for the videos elicited the second highest count of negative emotions $(N=22)$, and a high count of positive emotions $(N=83)$. Collectively, it was the process of producing the CSG mining videos (i.e., researching and writing their scripts, and making their videos) that elicited the highest counts of both positive and negative emotions in students' diaries. In contrast, the topics about which they learned (e.g., energy and CSG mining) elicited the lowest counts of emotions. Specifically, coding of the emotion diary entries revealed that only $8 \%$ of all emotions reported related directly to the topic of CSG mining. Students also reported quite high levels of interest during filmmaking, although a gradual decline in interest towards the end of the unit (Figure 2, point b) coincided with technical difficulties that emerged when students were trying to edit, upload, save and view their video files. Boredom was most frequently associated with activities in the first half of the unit, but very seldom in the latter part of the unit when filming was taking place. This is significant because the school's head science teacher selected the socio-scientific issue of CSG mining as he thought that it was a topical issue to which students could relate on an emotional level, particularly if they could empathize with key stakeholders (e.g., farmers). It appears, however, that it was the emotions associated with production of the artifact, rather than the topic, that dominated students' experiences and perceptions of the unit.

At interview, Miss Murphy explained that she afforded her students high levels of selfdirection in completing the video task, as she wanted them to develop their own evidenceinformed opinions about CSG mining through their research. By the end of the task, however, she felt that perhaps her class was afforded too much autonomy, resulting in little substantive engagement with the topic, as evidenced by their videos. Miss Murphy also doubted whether the students had formed definite opinions or ideas about CSG mining: 
Table 3

A summary of the count of positive and negative emotions reported in students' emotion diaries

\begin{tabular}{|c|c|c|c|}
\hline $\begin{array}{l}\text { Aspect of the Science } \\
\text { Unit That Elicited Emotions }\end{array}$ & $\begin{array}{l}\text { Count of } \\
\text { Positive } \\
\text { Emotions } \\
\quad(N)\end{array}$ & $\begin{array}{l}\text { Count of } \\
\text { Negative } \\
\text { Emotions } \\
(N)\end{array}$ & Examples \\
\hline The topic (e.g., energy, CSG mining) & 30 & 7 & $\begin{array}{l}\text { Enjoyment: "When we were } \\
\text { talking about energy." } \\
\text { Disappointment: "Watching the } \\
\text { video about global warming." }\end{array}$ \\
\hline $\begin{array}{l}\text { Activities not directly linked to the } \\
\text { CSG mining task (e.g., energy } \\
\text { experiments, watching videos) }\end{array}$ & 118 & 5 & $\begin{array}{l}\text { Enjoyment: "I enjoyed } \\
\text { experimenting with wind } \\
\text { turbines." } \\
\text { Frustration: "When our testing } \\
\text { wasn't working." }\end{array}$ \\
\hline Researching and writing scripts & 83 & 22 & $\begin{array}{l}\text { Excitement: “Can't wait to write } \\
\text { scripts because we have heaps } \\
\text { of information." } \\
\text { Frustration: "Because I can't find } \\
\text { or remember enough } \\
\text { information." }\end{array}$ \\
\hline Filmmaking & 119 & 26 & $\begin{array}{l}\text { Excitement: "We got to film some } \\
\text { of our film, we got to have a } \\
\text { laugh at each other." } \\
\text { Annoyed: "Because the video is } \\
\text { not working out properly." }\end{array}$ \\
\hline
\end{tabular}

Note: The far left-hand column indicates the aspect of the unit that elicited emotions. The far right-hand column provides examples of students' diary entries to illustrate each.

I wanted to get the kids to find their own understanding of the topic and their own opinion, but I think in doing that, I may have actually left it a little bit too open for them, and I think a lot of them have struggled with the science of the topic.... So I think that's why their videos lack the science. (Miss Murphy, Excerpt 8)

It appears that the emotions associated with producing the videos overshadowed the topic itself. In spite of the school's rationale for selecting CSG mining in the first place, Miss Murphy questioned whether the topic was, in fact, relevant to students, given that they did not present strong opinions about it or appear emotionally engaged with the characters in their videos. At interview, she pondered whether setting a video task about a different topic would have elicited a different response from her class:

I'm wondering if it was exactly the same task with a different topic, if it would be easier, because I still question whether they actually even think about what other people's points of view are. They sort of gloss over it in the videos. Is what they present in the videos, is that all they think about it, that they've put in? (Miss Murphy, Excerpt 9)

One student who expressed empathy for affected farmers was selected to participate in an interview as she made explicit reference to CSG mining in her emotion diary. She recorded feeling happy about what she had learned through her research: "I am really happy with the amount of work that I did and I know how CSG can be dangerous for farmers and their land and 
animals" (Suzanne, lesson 8.2). At interview, however, this student did not recall any strong emotions about CSG mining or any other topic in the unit. The strongest emotion that she recalled was happiness at making the video. Indeed, students most frequently recalled positive emotions associated with filmmaking at interview, which mirrors the findings that arose from the analysis of the emotion diaries.

In light of the high counts of positive emotions elicited by the video task (e.g., happiness, excitement, and enjoyment; Table 3), it appears that students' enthusiasm associated with filming the videos motivated them to complete the task, in spite of the challenges associated with working collaboratively and negotiating the technical aspects of filming and editing their videos. While Miss Murphy expressed concerns about whether the task would be completed on time, the students chose to spend time outside of class to finish their videos. Miss Murphy reflected on this, and on the high levels of enthusiasm for the task demonstrated by her class:

\section{Excerpt 10}

Miss Murphy: I still feel like I didn't have enough time. So it's a big job to get it all in a term, but I think they've done well and we wouldn't have got it done if they weren't so enthusiastic. They've spent a lot of time before school, at lunch and at home to get it done.

Researcher: So you've not seen this level of enthusiasm in previous units of work with them?

Miss Murphy: No, never ... definitely not ... By far the best time we've had.

While the case of Josh and Tim's group illustrates their regulation of negative emotions associated with working collaboratively to successfully complete the video task, these findings raise interesting questions about students' regulation of their positive emotions so that their learning remains focused on the topic, and is not overshadowed by an exciting and enjoyable task like filmmaking. We discuss this issue, and our earlier findings, in the following section.

\section{Discussion}

In this study, we sought to investigate students' emotion regulation during a unit focused on energy. Analyses of self-reported emotions data garnered through an emotions diary, supported by video recordings of lessons and end-of-project student and teacher interviews, revealed interesting trends in students' emotions and interest over the course of the unit, particularly as students worked collaboratively in small groups to complete an assessment task, a video on CSG mining. Collectively, these data helped to identify a salient event that occurred as a group of students were filming scenes for their video. The event centered around the interactions of two students in particular, Tim and Josh, and how they attempted to navigate the difficulties of filming a scene in the context of competing views about how it should be done. While Tim was more concerned about leading the group and the frustrations associated with filming in a way that he saw fit, Josh was angry and frustrated by having his ideas ignored. It appears that these experiences were not unique to Tim and Josh's group, with elevated counts of negative emotions like frustration, annoyance and anger reported across the class, as well as declining levels of interest, during the lessons in which filming and editing took place (lessons 8.1-10.1; Figures 2 and 4).

At interview, both Tim and Josh acknowledged the challenges of working in a group and the negative emotions associated with doing so. Negative emotions arose due to concerns about other students' contribution to the task, strident differences in opinion about how the task should be progressed, and technical difficulties associated with filming, uploading and editing their videos. 
Nonetheless, the group successfully produced a video about CSG mining for their assessment task. In this case, there is evidence to suggest that students regulated their emotions by identifying a common goal (to finish the task), by acknowledging their achievement aspiration (to get "good marks"), and preserve or restore positive relationships (to stay friends).

An analysis of which aspects of the energy unit elicited positive and negative emotions revealed that, collectively, the process of planning, scripting, filming and editing the CSG mining videos elicited the highest counts of both positive and negative emotions (Table 3 ). Few students reported that the topic of the unit-and in particular, CSG mining-aroused their emotions. Similarly, at interview, while few students could explain what they had learned about CSG mining, they enthusiastically recalled the fun that they had making the videos. So, while we expected the socio-scientific issue to engage students' emotions, it was the production of the video that dominated students' emotional experiences. Similarly, Miss Murphy was concerned by the lack of science generally communicated in the students' videos (Excerpt 8).

Collectively, these findings illuminate the students' regulation of their negative emotions during ongoing group work so as to achieve a planned outcome, like the production of a video about CSG mining. At the same time, it raised an unexpected finding about how students' emotions associated with the video task-particularly positive emotions-dominated their experience of the unit. In contrast, very few emotions were associated with the socio-scientific issue of CSG mining itself. As foreshadowed in the previous section, this raises questions about students' regulation of their positive emotions so that their learning remains focused on the topic. We now discuss each of these findings and their implications for emotions research.

\section{Student Regulation of Negative Emotions During Group Work}

The salient classroom event during lesson 8.3 highlighted in this paper (and depicted in Figure 5) saw some emotionally charged interactions among the group, particularly for Josh. It illustrates how interactions can increase or decrease a group's emotional energy. Josh recorded his feelings of frustration in his emotion dairy when his group did not work well together (Table 1).

Negative emotions arise when an individual's transactional needs are not met, and a person receives negative sanctions (Turner, 2009). During lesson 8.3, Josh felt excluded as his ideas for the video were not acknowledged or taken up by his peers. In this incident, in line with Turner's (2007) transactional needs theory, Josh's feelings of self-verification were undermined, as were his expectations of being part of the group and contributing to group decision-making. This led to the arousal of anger (Figure 5, 05:40, 10:10). As the lesson progressed, Josh distanced himself from the group (Figure 5, 20:44), which suggests that he was experiencing alienation, a secondorder emotion comprised mostly of disappointment-sadness and anger (at others and the situation), and fear of the consequences of not meeting the group's expectations (Turner, 2007). Alienation transforms negative emotions like anger into a withdrawal response that reduces an individual's willingness to participate in a group (Turner, 2007).

Collins (2004) conceives "social encounters as a market for social interactions of varying intensity" (p. 141). The way these encounters are valued is determined by the amount of emotional energy that is generated. Participants will attempt to repeat IRs that lead to high levels of emotional energy as they contribute to feelings of group solidarity. When these feelings begin to dissipate, individuals who are able will attempt to "reassemble" the group. These individuals tend to be those who have skills or "stock" that comprises the emotional energy resources and membership symbols that are the mutual focus of IRs. These stocks have been built up through prior IRs and are called upon if an individual sees benefit in investing social, material and emotional resources in a situation where there are opportunities for maximizing emotional energy. When Josh was angry, Tim could have chosen to ignore his outburst, but instead, he positioned himself close to Josh. 
From an IR perspective, this could be interpreted as a "repair ritual" (Collins, 2004) or an attempt to build solidarity, so as to draw Josh back into the group and generate emotional energy. This was Tim's best option for achieving the long-term goal of a good grade for the assessment task, while the repair ritual itself may have helped Josh to regulate his anger. Eventually, group solidarity was restored and filming for the scene was completed successfully.

Josh explained at interview that the challenges of working in a group and dealing with technical issues were overcome by the desire to finish the task successfully and achieve a good grade. Miss Murphy also recalled her students' persistence and not giving up in the face of challenges (Excerpt 7). At the same time, Josh recalled a realization that the task was not worth losing friendships over, so a motivation to preserve or restore positive relationships was also important (Excerpt 5). For this group, the video artifact was a symbol of the group's solidary and invested emotional energy (Collins, 2004; Turner, 2009). The students were motivated to increase their emotional energy by regulating their emotions during group interactions so they could achieve their aim of finishing the film and achieving a good grade. Milne and Otieno (2007) suggest that it is the responsibility of the teacher to identify symbols that will serve as a mutual focus for learning so that IRs lead to the intended learning goals. In this case, it was the video, rather than the socio-scientific issue, that became the symbol of mutual focus. In her interview, Miss Murphy recognized that this was the case as she reflected on ways she could modify the unit of work in future to enhance the relevance of the topic to students.

Like Josh, Tim also reported feeling negative emotions that arose from working in the group. At interview, Tim explained that while science was his favorite subject (Excerpt 4), he did not enjoy the video task. He found navigating the multiple perspectives and opinions of his group members difficult, which aroused negative emotions like frustration (Table 2), and he commented that he would have preferred an alternative task that required students to work individually or in pairs. This is not surprising, given that students will avoid experiences and interactions that drain emotional energy and arouse negative emotions (cf. Collins, 2004; Turner, 2009). Like Josh, Tim was motivated to overcome the challenges of working in a group as they shared a common goal to do a good job of the video task, and by recognizing that "other people had opinions too" (Excerpt 4). Tim's situation highlights that while it is important to acknowledge negative emotions that arise in the classroom, there must be a motivation to regulate them so as to achieve particular goals and planned outcomes. This motivation, according to Collins (2004), is the desire to build emotional energy. Notwithstanding the importance of achieving particular learning goals, Tim's comment about feeling annoyed with his group (Excerpt 4) also reminds us of the importance of resolving negative emotions, as unresolved negative emotions or the ongoing perpetuation of low emotional energy can impact negatively on students' interest in and attitudes toward science (Olitsky \& Milne, 2012).

Engaging students in group work is a common pedagogical strategy in the science classroom. Indeed, the provision of learning environments that support students' autonomy and cooperation can positively influence their emotions (Pekrun, 2006). Miss Murphy's decision to "leave the task open" to her students as they worked collaboratively on the video task (Excerpt 8) presented a valuable opportunity to regulate their own learning and build a sense of competence in a group context. Pekrun (2006) cautions, however, that negative emotions like frustration can arise if such learning environments are too challenging for students, which calls for teachers to "fine-tune the affordances and constraints of these learning environments to students' capabilities” (p. 335).

Collectively, this salient classroom event offers some important considerations for engaging students in ongoing group work. In this case, Josh and Tim's group came to successfully regulate their negative emotions on their own through their motivation to restore emotional energy through successful interactions that built group solidarity by investing in a shared symbol (the video task). 
This came about through a desire to finish the task successfully, to achieve good grades, and to maintain positive relationships with each other; however, it was a belief that the final product, the video, was worthwhile that most strongly influenced students' regulation of their emotions.

\section{Student Regulation of Positive Emotions in Science}

Analyses of students' emotion diaries revealed, not surprisingly, that different classroom activities aroused different emotions and levels of interest. For example, enjoyment corresponded with high levels of interest when students were engaged in scaffolded energy experiments that involved manipulating equipment and making observations (lessons 3.2 and 3.3; see Figure 4). Similarly, the commencement of filming elicited higher counts of positive emotions like enjoyment, enthusiasm, and happiness (Figure 4, point b), and higher levels of interest, than previous lessons (Figure 2). During the last lessons in the unit, filming, uploading, and editing the videos was associated with declining interest levels (Figure 2, point a) and higher counts of negative emotions.

Overall, it was not the negative emotions associated with the video task that proved memorable for students; it was the fun, enjoyment, and excitement of working with their friends on a novel task that students recalled with exuberance. Miss Murphy noted at interview that she had not observed such high levels of enthusiasm in her students before (Excerpt 10). In this way, the notion of regulating students' positive emotions becomes equally as significant as the regulation of their negative emotions. While positive emotions can be valuable for developing students' situational interest in science through an exciting or motivating activity like filmmaking, it is unlikely to develop into more enduring, individual interest in science unless it is maintained over time, and repeated opportunities are presented to reengage with particular content (Hidi \& Renninger, 2006). In this case, if teaching and learning in Miss Murphy's class returned to less engaging activities and forms of representation in the following term, the CSG mining video task would be unlikely to have any long-term impact on students' interest in science.

The excitement of producing the videos also raised a concern from Miss Murphy who was worried that students focused too heavily on the task itself and not on the socio-scientific issue, which led to less science being included in students' productions than she would have liked (and, indeed, little recollection of what they had learned during the end-of-project interviews). In this case, it appears that the positive emotions associated with the task took students' focus away from their learning of the content. This may have had something to do with the nature of the socioscientific issue, in that it was not personally relevant, as recognized by Miss Murphy (Excerpt 9) and reflected by the very few references to CSG mining in students' emotion diaries (Table 3). At the same time, Miss Murphy thought that a lot of students "struggled with the science" and she wondered whether she left the task "a little too open for them" (Excerpt 8).

While "activating" positive emotions (such as enjoyment and pride) can encourage and moderate students' interest in learning and enhance both their intrinsic and extrinsic motivation, like negative emotions, they can also "consume cognitive resources by focusing attention on the object of the emotion" (Pekrun, 2006, p. 326, emphasis added). This is significant because positive emotions can reduce cognitive resources required to attend to the purpose of the task and impair cognitive performance. In this study, it is clear that while the positive emotions associated with filmmaking enhanced students' interest and motivation to complete the task, they focused students' attention on the object of their emotions-the videos-and consumed cognitive resources required to focus on the purpose of the task; learning about CSG mining. So, while positive emotions like enjoyment can enhance learning by helping students to focus on a given task, they can, in certain circumstances, be "detrimental for important outcomes like achievement" (Pekrun, 2006, p. 327). 
The findings of this study suggest that a balance must be struck between providing interesting and motivating tasks in science that foster students' positive emotions, while ensuring that adequate cognitive resources are available for students to focus on the underlying purpose of the task, or the desired science learning. Indeed, constructing "emotionally beneficial" learning environments is a challenging undertaking that requires teachers to design "cognitively activating tasks" while "tailoring task demands and goal structures to the developmental needs of students, providing autonomy support, and using informational, mastery-orientated feedback about learning" (Pekrun \& Linnenbrink-Garcia, 2014, p. 671). For extended group work tasks, like the one in our study, explicit scaffolding that helps students to remain focused on the intended science learning-particularly if it is cognitively challenging-may be an important factor in regulating students' positive emotions so that they do not get the better of them. This finding mirrors earlier research conducted by the first and third authors that found that engaging students in a novel form of representation in science calls for explicit scaffolding to ensure that students focus sufficiently on the desired content and communicate their learning appropriately. In their study, Tomas and Ritchie (2015) found that middle-school students, who wrote short stories about a socio-scientific issue, often neglected to include sufficient science in their writing, instead preferring to focus on writing a good story. Collectively, these findings suggest that novel learning activities must be carefully managed by the classroom teacher to ensure that the topic is relevant and equally motivating as the task itself, and that students' positive emotions do not direct them away from the intended learning. Nonetheless, it is important that students are exposed to a diverse range of representations in science over time, recognizing that different modes will stimulate interest for different students (cf. Tim, who would have preferred producing a PowerPoint ${ }^{\mathrm{TM}}$ presentation over a video).

\section{Concluding Remarks}

This study begins to illuminate students' emotion regulation-particularly of their negative emotions-as they work together to achieve a planned outcome in science. According to Jacobs and Gross (2014), it is important to understand what motivates students to regulate their emotions in particular educational contexts. As shown by the experiences of the participants in our study, this is significant because unresolved negative emotions like frustration, anger, and annoyance can impact negatively on students' engagement with and interest in science. Specifically, we found that sharing common goals and investing in a symbol of mutual focus motivated students to regulate their emotions so as to build group solidarity and foster positive emotional energy. At the same time, while novel tasks like filmmaking can also elicit positive emotions and emotional energy, they must be carefully planned, managed, and scaffolded to ensure that the topic is relevant, and adequate focus remains on the intended learning, as regulating positive emotions in this context is equally as important.

We believe that the findings of this study offer new insights into how students' emotions can impact on their interest, motivation, engagement, and learning in science. These insights have implications for both classroom practice and for further research. First, it is important for teachers to recognize the potential for emotions to influence students' resolve to complete given tasks, and their motivation to engage with science in the future or not. Identifying students' emotional responses to learning science is an important preliminary step. Emotion diaries can be effective tools for teachers to analyze classroom events so as to inform instructional decisions that best support students' emotion regulation and learning in the science classroom, particularly in the context of group activities. Requiring students to diarize their emotions in class may, in itself, enhance their ability to regulate their emotions by making them more cognizant of their own feelings and that of their peers (cf. Matthews et al., 2002). 
Second, we propose that further research is required to explore the relationship between students' interest in science, the regulation of their emotions, and learning. Such research might call for the qualitative procedures described in this study to be used in conjunction with highinference measures (e.g., the Positive Affect Negative Affect Schedule; see Tomas \& Ritchie, 2012), so as to understand better the link between students' learning and emotional experiences in science. Additionally, research might consider how teachers can provide explicit structures to support students to regulate their emotions in the classroom and remain focused on their learning, such as mindfulness and cooperative learning techniques, and establish classroom environments that are conducive to building solidarity and high emotional energy. Such lines of inquiry are needed to assist teachers to recognize the emotional responses of students in the science classroom and to use these responses as a resource for further interactions and learning, as suggested by Milne and Rubin (2011).

\section{References}

Ainley, M. (2007). Being and feeling interested: Transient state, mood, and disposition. In P. A. Schutz \& R. Pekrun (Eds.), Emotion in education (pp. 141-157). San Diego, CA: Elsevier, Inc.

Ainley, M., \& Ainley, J. (2011). Student engagement with science in early adolescence: The contribution of enjoyment to students' continuing interest in learning about science. Contemporary Educational Psychology, 36, 4-12.

Ainley, M., Corrigan, M., \& Richardson, N. (2005). Students, tasks and emotions: Identifying the contribution of emotions to students' reading of popular culture and popular science texts. Learning and Instruction, 15, 433-447.

Alsop, S. (2011). The body bites back? Cultural Studies of Science Education, 6, 622-623.

Baumeister, R., Bratslavsky, E, Muraven, M., \& Tice, D. M. (1998). Ego-depletion: Is the active self a limited resource. Journal of Personality and Social Psychology, 74, 1252-1265.

Bellocchi, A., \& Ritchie, S. M. (2015). "I was proud of myself that I didn't give up and I did it": Experiences of pride and triumph in learning science. Science Education, 99, 638-668.

Blair, C. (2002). School readiness: Integrating cognition and emotion in a neurobiological conceptualization of child functioning at school entry. American Psychologist, 57, 111-127.

Boekaerts, M. (2007). Understanding students' affective processes in the classroom. In P. Schutz, R. Pekrun, \& G. Phye (Eds.), Emotion in education (pp. 37-56). San Diego, CA: Academic Press.

Boekaerts, M. (2011). Emotions, emotion regulation, and self-regulation of learning. In B. J. Zimmerman \& D. H. Schunk (Eds.), Handbook of self-regulation of learning and performance (pp. 408-425). New York, NY: Routledge.

Broughton, S. H., Sinatra, G. M., \& Nussbaum, E. M. (2013). "Pluto has been a planet my whole life!" Emotions, attitudes, and conceptual change in elementary students' learning about Pluto's reclassification. Research in Science Education, 43, 529-550.

Chiang., W., \& Liu, C. (2014). Scale of academic emotion in science education: Development and validation. International Journal of Science Education, 36, 908-928.

Collins, R. (2004). Interaction ritual chains. Princeton, NJ: Princeton University Press.

Do, S. L., \& Schallert, D. L. (2004). Emotions and classroom talks: Toward a model of the role of affect in students' experiences of classroom discourse. Journal of Educational Psychology, 96, 619-634.

Ekman, P., \& Friesen, W. V. (1975). Unmasking the face. A guide to recognizing emotions from facial clues. Upper Saddle River, NJ: Prentice-Hall.

Ekman, P., \& Friesen., W. V. (1978). Facial Action Coding System: A technique for the measurement of facial movement. Palo Alto: Consulting Psychologists Press.

Erickson, F. (1986). Qualitative methods in research on teaching. In M. C. Wittrock (Ed.), Handbook of research on teaching (pp. 119-161). New York, NY: Macmillan.

Fortus, D. (2014). Attending to affect. Journal of Research in Science Teaching, 51, 821-835.

Goetz, T., Frenzel, A. C., Pekrun, R., Hall, N. C., \& Lüdtke, O. (2007). Between-and withindomain relations of studentsü academic emotions. Journal of Educational Psychology, 99, 715-733. 
Goetz, T., Pekrun, R., Hall, N. C., \& Haag, L. (2006). Academic emotions from a socio-cognitive perspective: Antecedents and domain specificity of students' affect in the context of Latin instruction. British Journal of Educational Psychology, 76, 289-308.

Graziano, P. A., Reavis, R. D., Keane, S. P., \& Calkins, S. D. (2007). The role of emotion regulation in children's early academic success. Journal of School Psychology, 45, 3-19.

Gross, J. J. (1998). The emerging field of emotion regulation: An integrative review. Review of General Psychology, 2, 271-299.

Heddy, B. C., \& Sinatra, G. M. (2013). Transforming misconceptions: Using transformative experience to promote positive affect and conceptual change in students learning about biological evolution. Science Education, 97, 723-744.

Hidi, S., \& Renninger, K. A. (2006). The four-phase model of interest development. Educational Psychologist, 49, 111-127.

Jacobs, S. E., \& Gross, J. J. (2014). Emotion regulation in education: Conceptual foundations, current applications and future directions. In R. Pekrun, \& L. Linnenbrink-Garcia (Eds.), International handbook of emotions in education (pp. 183-201). New York, NY: Routledge.

Keltner, D., \& Ekman, P. (2000). Facial expression of emotion. In M. Lewis, \& J. Haviland-Jones (Eds.), Handbook of emotions (pp. 236-249). New York, NY: Guilford Publications, Inc.

Kershner, R., Warwick, P., Mercer, N., \& Kleine Staarman, J. (2012). Primary children's management of themselves and others in collaborative group work: 'Sometimes it takes patience ...'. Education 3-13, 42, 201-216.

King, D., Ritchie, S., Sandhu, M., \& Henderson, S. (2015). Emotionally intense science activities. International Journal of Science Education, 37, 1886-1914.

Lawler, E. J. (2001). An affect theory of social exchange. American Journal of Sociology, 107, 321-352.

Lewis, M. (2008). Self-conscious emotions: Embarrassment, pride, shame, and guilt. In M. Lewis, J. M. Haviland-Jones, \& L. Feldman Barrett (Eds.), Handbook of emotions (pp. 742-756). New York, NY: The Guilford Press.

Linnenbrink-Garcia, L., \& Pekrun, R. (2011). Students' emotions and academic engagement: Introduction to the special issue. Contemporary Educational Psychology, 36, 1-3.

Lundegard, I. (2007). Self, values, world-Young people in dialogue on sustainable development. In J. Ohman (Ed.), Values and democracy in education for sustainable development-Contributions from Swedish research (pp. 123-144). Stockholm: Liber.

Matthews, G., Zeidner, M., \& Roberts, R. D. (2002). Emotional intelligence: Science and myth. Cambridge, MA: MIT Press.

Milne, C., \& Otieno, T. (2007). Understanding engagement: Science demonstrations and emotional energy. Science Education, 10, 523-553.

Milne, C, \& Rubin, K. (2011). Embodying emotions: Making transactions explicit in science learning transactions. Cultural Studies of Science Education, 6, 625-633.

MacCann, C., Fogarty, G. J., Zeidner, M., \& Roberts, R. D. (2011). Coping mediates the relationship between emotional intelligence (EI) and academic achievement. Contemporary Educational Psychology, 36, 60-70.

Morris, H. (2014). Socioscientific issues and multidisciplinarity in school science textbooks. International Journal of Science Education, 36, 1137-1158.

Nett, U. E., Goetz, T., \& Hall, N. (2011). Coping with boredom in school: An experience sampling perspective. Contemporary Educational Psychology, 36, 49-59.

Olitsky, S. (2007). Promoting student engagement in science: Interaction rituals and the pursuit of a community of practice. Journal of Research in Science Teaching, 44, 33-56.

Olitsky, S., \& Milne, C. (2012). Understanding engagement in science education: The psychological and the social. In B. J. Fraser, K. Tobin, \& C. J. McRobbie (Eds.), Second international handbook of science education (pp. 19-33). Netherlands: Springer.

Orlander, A., \& Wickman, P. (2011). Bodily experiences in secondary school biology. Cultural Studies of Science Education, 6, 569-594. 
Osborne, B., Simon, S., \& Collins, S. (2003). Attitudes towards science: A review of the literature and its implications. International Journal of Science Education, 25, 1049-1079.

Pekrun, R. (2006). The control-value theory of achievement emotions: Assumptions, corollaries, and implications for educational research and practice. Educational Psychology Review, 18, 315-341.

Pekrun, R. (2000). A social-cognitive, control-value theory of achievement emotions. In J. Heckhausen (Ed.), Motivational psychology of human development (pp. 143-163).Elsevier: Oxford, England.

Pekrun, R., \& Linnenbrink-Garcia, L. (2014). Conclusions and future directions. In R. Pekrun, \& L. Linnenbrink-Garcia (Eds.), International handbook of emotions in education (pp. 659-675). New York, NY: Routledge.

Pekrun, R., Goetz, T., Frenzel, A. C., Barchefield, P., \& Perry, R. (2011). Measuring emotions in students' learning and performance: The Achievement Emotions Questionnaire (AEQ). Contemporary Educational Psychology, 36, 36-48.

Ritchie, S. M., Tomas, L., \& Tones, M. (2011). Writing stories to enhance scientific literacy. International Journal of Science Education, 33, 685-707.

Ritchie, S. M., \& Tomas, L. (2013). Designing an innovative approach to engage students in learning science: The evolving case of hybridized writing. In L. V. Shavinina (Ed.), The Routledge international handbook of innovation education (pp. 385-395). New York, NY: Routledge.

Ritchie, S. M., Hudson, P., Bellocchi, A., Henderson, S., King, D., \& Tobin, K. (2016). Evolution of selfreporting methods for identifying discrete emotions in science classrooms. Cultural Studies of Science Education, doi: 10.1007/s11422-014-9607-y

Rosenberg, E. L. (2005). Introduction: The study of spontaneous facial expressions in psychology. In P. Ekman, \& E. L. Rosenberg (Eds.), What the face reveals: Basic and applied studies of spontaneous expressing using the Facial Action Coding System (FACS) (pp. 3-18). Oxford: Oxford University Press.

Stake, R.E. (1995). The art of case study research. Thousand Oaks, CA: Sage Publications.

Tobin, K. (2005). Building enacted science curricula on the capital of learners. Science Education, 89, 577-594.

Tomas, L., Ritchie, S. M., \& Tones, M. (2011). Attitudinal impact of hybridized writing about a socioscientific issue. Journal of Research in Science Teaching, 48, 878-900.

Tomas, L., \& Ritchie, S. M. (2012). Positive emotional responses to hybridised writing about a socioscientific issue. Research in Science Education, 42, 25-49.

Tomas, L., \& Ritchie, S. M. (2015). The challenge of evaluating students' scientific literacy in a writingto-learn context. Research in Science Education, 45, 41-58.

Tuan, H. L., Chin, C. C., \& Shieh, S. H. (2005). The development of a questionnaire for assessing students' motivation toward science learning. International Journal of Science Education, 27, 639-654.

Turner, J. H. (2007). Human emotions: A sociological theory. New York, NY: Routledge.

Turner, J. H. (2009). The sociology of emotions: Basic theoretic arguments. Emotion Review, 1, 340-354.

Wosnitza, M., \& Volet, S. (2005). Origin, direction and impact of emotions in social online learning. Learning and Instruction, 15, 449-464.

Zembylas, M. (2007). The power and the politics of emotions in teaching. In P. A. Schutz, \& R. Pekrun (Eds.), Emotion in education (pp. 285-301). San Diego, CA: Elsevier, Inc. 